\title{
ANALISIS DAN KONSEP PENANGANAN AKTINIDA MINOR DALAM LIMBAH PLTN MENGGUNAKAN TEKNOLOGI ADS
}

\author{
Silakhuddin \\ Pusat Teknologi Akselerator dan Proses Bahan, BATAN \\ Jl. Babarsari Kotak Pos 6101 ykbb, Yogyakarta 55010
}

\begin{abstract}
ABSTRAK
ANALISIS DAN KONSEP PENANGANAN AKTINIDA MINOR DALAM LIMBAH PLTN MENGGUNAKAN TEKNOLOGI ADS. Kandungan unsur-unsur aktinida minor (americium, neptunium dan curium) dalam bahan bakar bekas hasil operasi PLTN jenis PWR telah dihitung menggunakan program VISTA. Perhitungan dilakukan dengan parameter-parameter: pengkayaan 3,968\%, daya $1000 \mathrm{MWe}$ dan nilai fraksi bakar $60 \mathrm{MWd} / \mathrm{kg}$. Hasil perhitungan menunjukkan bahwa pada operasi PWR-UOX menghasilkan total aktinida minor sejumlah 16,205 kg/tahun, dan untuk PWR-MOX sebesar 43,471 kg/tahun. Juga dibahas konsep penggunaan teknologi ADS untuk mentransmutasi limbah unsur-unsur aktinida minor yang terkandung dalam bahan bakar bekas. Hasil bahasan menunjukkan bahwa dengan satu ADS 400 MWth akan dapat melayani 7 buah PWR-UOX, dan dalam sistem PWR yang menggunakan bahan bakar UOX dan MOX maka satu ADS akan melayani 3 buah sistem PWR.
\end{abstract}

Kata kunci: limbah nuklir, aktinida minor, PLTN, ADS

\section{ABSTRACT}

THE ANALYSIS AND HANDLING CONCEPT OF MINOR ACTINIDES OF NPP'S WASTE BY USING ADS TECHNOLOGY. The contents of minor actinide elements (americium, neptunium and curium) on the spent fuel inventory from PWR operation of NPP have been calculated using VISTA program. The calculation used parameters: enrichment $3.968 \%$, power $1000 \mathrm{MWe}$ and burn-up is $60 \mathrm{MWd} / \mathrm{kg}$. The result of calculation showed that the arising of minor actinide elements on the spent fuel is $16.205 \mathrm{~kg} / \mathrm{year}$ and $43.471 \mathrm{~kg} / \mathrm{year}$ for PWR-UOX and PWR-MOX respectively. It is also discussed a concept of the use of ADS technology for transmuting the minor actinide elements contained in spent fuels. The result of the discussion showed that an ADS of $400 \mathrm{MW}$ th will serve 7 PWRs-UOX, and on the PWR system using UOX and MOX fuels an ADS will serve 3 PWRs.

Key words: nuclear waste, minor actinide, NPP, ADS.

\section{PENDAHULUAN}

$T$ im mbulnya kesadaran publik yang tidak dapat diabaikan tentang perlunya kontribusi energi nuklir terhadap pembangunan yang berkelanjutan telah menuntut reevaluasi rumusan strategi pengembangan energi nuklir untuk dasawarsa mendatang. Efisiensi sumber energi, keramahan lingkungan dan keefektifan harga akan menjadi pilar penting dalam kajian dan evaluasi tersebut. Pada era mendatang energi nuklir dapat memainkan peran penting dalam menanggapi perhatian publik ini.

Sekalipun sumber uranium yang diketahui memberikan lebih dari seratus tahun pasokan dengan taman daya nuklir (nuclear power park) saat ini, tetapi tidak dapat dilupakan bahwa LWR hanya memanfaatkan kurang satu persen kandungan energi uranium yang ditambang, sisa energi tersimpan di dalam bahan bakar bekas dan depleted uranium dalam proses pengkayaan. Dengan demikian strategi pertama yang perlu dijalankan adalah mengubah daur bahan bakar yang dapat membangkitkan fraksi energi yang lebih tinggi yang terkandung dalam uranium tertambang. Cara ini akan mengurangi tekanan terhadap kekurangefisienan penggunaan bahan bakar.

Perhatian kedua adalah soal emisi rumah kaca dan juga dampak limbah secara umum telah menjadi perhatian publik yang besar. Energi nuklir tidak menghasilkan gas rumah kaca, tetapi limbah sangat radiotoksik yang ditimbulkan telah memicu debat publik. Cara-cara yang lebih ramah lingkungan dalam memproduksi energi nuklir dengan mengurangi limbah nuklir khususnya HLW, akan menaikkan potensi energi nuklir di masa depan. Inilah strategi kedua bagi pengembangan energi nuklir dengan menghadirkan sistem reaktor maju yang salah satu maksudnya untuk mengurangi radiotoksisitas dalam limbah nuklir.

Masalah keefektifan harga menjadi pertimbangan penting dalam merumuskan strategi ketiga. Dalam hal ini sekalipun LWR akan terus dapat menutupi sebagaian besar kebutuhan energi nuklir, beberapa reaktor maju yang 
menggunakan kandungan energi sisa dalam bahan bakar bekas dan memberlakukan limbah aktinida sebaiknya diintegrasikan ke dalam sistem untuk membantu energi nuklir memenuhi harapan jangka panjang. Akan tetapi karena kelayakan ekonomik dari reaktor maju belum terbukti, rasio dari reaktor-reaktor konvensional dan maju sebaiknya tetap tinggi dalam jangka pendek hingga menengah guna mengurangi kenaikan harga per satuan daya yang dihasilkan.

Unsur-unsur aktinida minor (minor actinides, selanjutnya disingkat MA) memberikan kontribusi yang tinggi sifat radiotoksisitas dalam bahan bakar bekas PLTN, khususnya karena umurnya yang sangat panjang. Untuk memberikan gambaran seberapa besar radiotoksisitas MA dalam bahan bakar bekas, disajikan hasil estimasi berdasar perhitungan mengenai produk unsur-unsur MA yang terdapat pada bahan bakar bekas PLTN. Perhitungan menggunakan program simulasi VISTA yang merupakan program yang telah ditetapkan dan digunakan oleh kelompok kerja (working group) IAEA ${ }^{(1)}$. Selanjutnya dibahas tentang konsep transmutasi unsurunsur MA tersebut menggunakan teknologi Accelerator Driven System (ADS) sebagai suatu opsi solusi penanganan limbah unsur-unsur MA. Hasil estimasi permasalahan dan solusi tersebut diharapkan akan dapat memberikan sumbangan bagi rumusan kebijakan pengembangan energi nuklir di masa depan.

\section{AKTINIDA MINOR DALAM SISTEM DAUR BAHAN BAKAR}

Aktinida minor merupakan unsur-unsur yang terbentuk pada bahan bakar bekas PLTN dari reaksi tangkapan neutron oleh inti-inti uranium. Unsur-unsur tersebut terdiri atas nuklida-nuklida: Np-237, Am-241, Am-242m, Am-243, Cm-242 dan Cm-244. Konsentrasi massa dalam bahan bakar bekas hanya $0,11 \%$ tetapi bersama dengan plutonium memberikan radiotoksisitas sebesar $100 \mathrm{~Sv} / g r$ dan meluruh untuk jangka waktu ratusan ribu tahun ${ }^{(2)}$. Penanganan unsur-unsur MA tidak terlepas dari sistem daur bahan bakar yang diterapkan.

Daur bahan bakar pertama yang dikelompokkan sebagai "teknologi saat ini" dan disebut sebagai daur terbuka, yang meliputi daur sekali proses (once through cycle), daur proses ulang konvensional dan daur DUPIC. Dalam daur sekali proses seluruh bahan bakar bekas PWR masuk ke dalam penyimpanan akhir, sedangkan dalam daur proses ulang konvensional unsur plutonium dipakai untuk sekali penggunaan dalam reaktor berbahan bakar MOX, dan selanjutnya sebagai limbah. Dalam daur model DUPIC seluruh bahan bakar bekas dari LWR digunakan langsung sebagai bahan bakar reaktor air berat CANDU, dan kemudian seluruhnya sebagai limbah. Dalam kelompok daur ini semua unsur MA langsung dikemas sebagai limbah nuklir untuk penyimpanan geologik. Dari segi keselamatan lingkungan skenario tanpa proses akan lebih baik, tetapi kurang memperhatikan segi keberlangsungan penyediaan bahan bakar. Skenario daur ulang memberikan sumbangan cukup berarti bagi keberlangsungan penyediaan bahan bakar tetapi sebaliknya mempunyai resiko keselamatan lingkungan karena dipisah dan dipungutnya unsur-unsur yang mempunyai radiotoksisitas tinggi.

Kelompok kedua yang didasarkan pada daur tertutup parsial yang tujuannya menghindari plutonium masuk dalam limbah dan secara terus menerus dipungut dalam fasilitas PUREX (plutonium extraction) untuk selanjutnya digunakan sebagai bahan bakar MOX. Dalam kelompok daur ini unsur-unsur aktinida minor langsung dikemas sebagai limbah. Efisiensi penggunaan bahan bakar lebih baik dari daur terbuka dan menghindari plutonium dari penyalahgunaan. Daur ini masih menyediakan limbah toksik dari MA dan produk-produk fisi.

Kelompok ketiga yang disebut sebagai daur tertutup sepenuhnya dalam arti ideal adalah seluruh limbah sudah tidak mengandung sifat radiotoksisitas tinggi berumur panjang. Daur ini juga disebut sebagai daur bahan bakar maju (advanced fuel cycle $=\mathrm{AFC}$ ) yang dimaksudkan untuk mengefisienkan penggunaan bahan bakar dan mengurangi radiotoksisitas yang tinggi pada HLW yaitu dengan menambahkan modul pemisahan MA dalam daur ulang standar, kemudian melakukan proses transmutasi unsur-unsur MA untuk menghilangkan sifat umur radiotoksisitas yang panjang. Dalam suatu fasilitas yang disebut advanced PUREX, bahan bakar bekas diurai menjadi 3 kelompok. Kelompok pertama adalah produk-produk fisi dan metal berat selain transuranium yang kemudian digudangkan sebagai HLLW. Kelompok kedua adalah unsur-unsur plutonium yang selanjutnya masuk ke fasilitas fabrikasi bahan bakar MOX untuk PWR-MOX. Kelompok ketiga adalah unsur-unsur MA yang dikirim ke transmuter MA misalnya suatu fasilitas ADS. Jadi sistem yang dikenal dengan double strata ini terdiri atas PWRUOX, PWR-MOX dan Transmuter MA. Skema dari daur bahan bakar maju diperlihatkan pada Gambar $1^{(3)}$. 


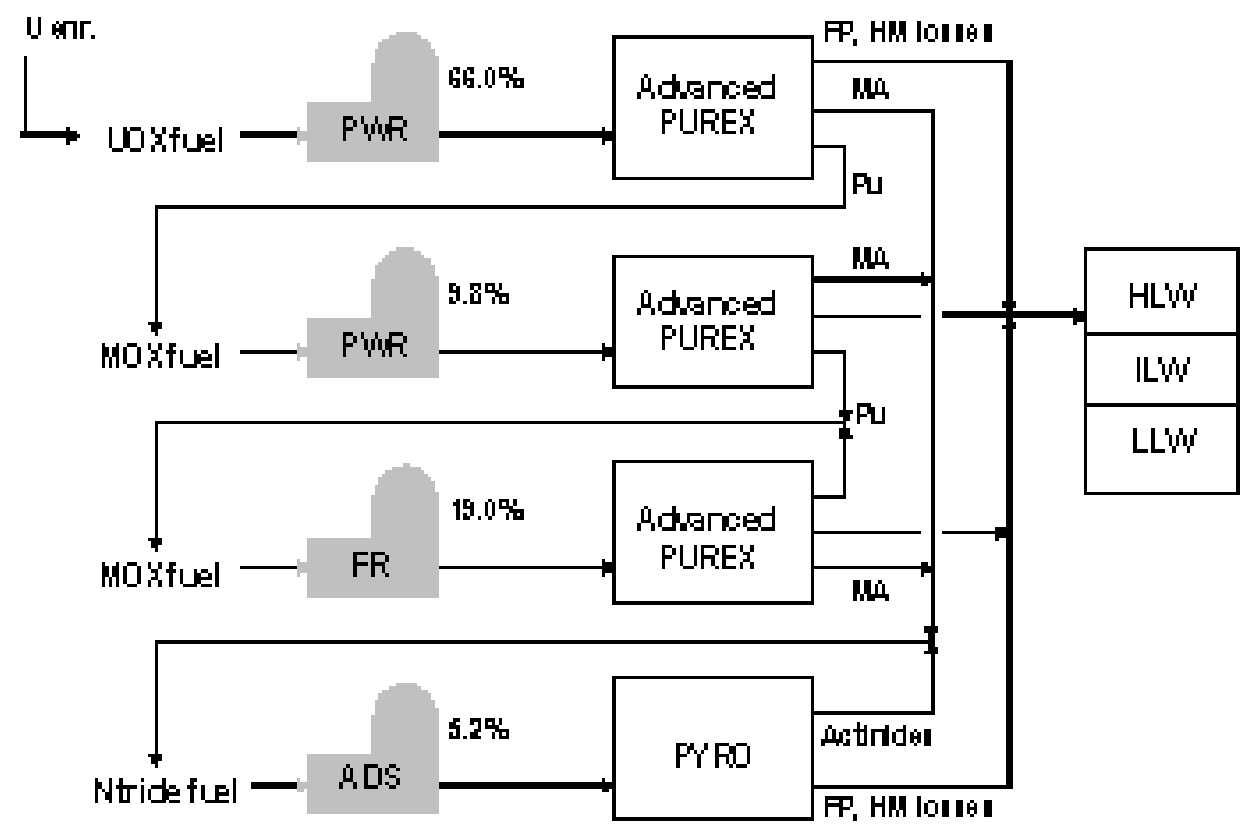

Gambar 1. Skema daur proses ulang maju, unsur MA dibakar dalam ADS

\section{TATA KERJA}

\section{Obyek Perhitungan}

Untuk subsistem PWR-UOX akan diambil nilai fraksi-bakar (burn-up) $60 \mathrm{MWd} / \mathrm{kg}$ dan daya $1000 \mathrm{MWe}$. Nilai-nilai ini diambil karena pada umumnya reaktor nuklir daya jenis PWR beroperasi pada kisaran nilai tersebut. PWR-MOX diasumsikan beroperasi pada nilai fraksi-bakar dan daya yang sama dengan PWR-UOX. Setiap subsistem akan dihitung produksi tahunan unsur-unsur MA dan kemudian akan ditinjau peranan ADS dalam penanganan produk-produk MA tersebut.

\section{Sarana : Program Simulasi VISTA}

Program ini dapat menghitung secara luas tentang proses daur bahan bakar dari tahun ke tahun untuk periode yang panjang tentang: keperluan daur bahan bakar nuklir untuk seluruh tipe reaktor. Jumlah uranium alam, konversi dan fabrikasi juga dapat diestimasi. Untuk keperluan proses di ujung belakang (back end) daur, dapat diestimasi secara kuantitatif maupun kualitatif (komposisi isotopik) dari bahan bakar yang selesai terpasang (unloaded).

Input dalam program ini meliputi:

1. Opsi daur, dalam hal ini dipilih daur once through atau UOX+MOX dalam LWR

2. Tipe reaktor (opsinya: PWR, BWR, PHWR, RBMK, AGR, GCR, WWER)

3. Tipe bahan bakar; hanya PWR dan BWR dianggap tipe-tipe yang dapat membakar bahan bakar dari material hasil reprosesing. Seluruh tipe yang lain hanya mempunyai satu pilihan yaitu UOX. Untuk PWR dan BWR dapat dipilih UOX dan MOX.

4. Daya Reaktor (MWe)

5. Faktor beban $(\%)$

6. Efisiensi termal (\%)

7. Fraksi bakar (burn-up) bahan bakar (GWD/t)

Output yang berhubungan dengan perhitungan ini terdiri atas:

1. Penggunaan uranium untuk MOX 
2. Produksi listrik

3. Pelepasan bahan bakar bekas

4. Jumlah Pu yang diproses

5. Jumlah aktinida minor dalam pemrosesan limbah

6. Jumlah produk fisi di dalam pemrosesan limbah

Model perhitungan dasar yang disajikan, adalah menghitung keperluan material dan pelayanan tahunan dan juga munculnya material pada teras setimbang. Sehingga loading teras awal atau pelepasan selama periode pemasangan bahan bakar kembali (refuelling) atau akhir dari umur reaktor tidaklah dipandang. Juga diasumsikan bahwa jumlah pengurangan massa dari logam berat (U, Pu, Yh, MA dII) dipandang sebagai akumulasi produk fisi, walaupun sebenarnya ada sebagian kecil pengurangan massa lain selama operasi reaktor.

Pada ujung akhir daur, jumlah pelepasan bahan bakar bekas tahunan, jumlah pemrosesan kembali bahan bakar bekas tahunan, jumlah penggudangan bahan bakar bekas tahunan, jumlah material yang diproses kembali tahunan ( $\mathrm{U}$ atau $\mathrm{Pu}$ ), jumlah material-material aktinida minor, produk fisi dan limbah level tinggi dihitung.

\section{HASIL DAN PEMBAHASAN}

\section{Hasil kalkulasi unsur-unsur MA}

Hasil kalkulasi dengan program VISTA dari timbunan tahunan (dalam satuan ton) yang terkandung dalam bahan bakar bekas PLTN PWR-UOX 1000 MWe untuk nilai fraksi bakar (BU) 60 MWd/kg ditunjukkan pada Tabel 1, dan untuk sistem PWR UOX dan MOX dengan daya dan fraksi bakar yang sama ditunjukkan pada Tabel 2.

Tabel 1. Kandungan nuklida-nuklida dalam bahan bakar PWR-UOX

\begin{tabular}{|c|c|c|}
\hline \multirow{2}{*}{ Isotop } & \multicolumn{2}{|c|}{ Kandungan (ton) } \\
\cline { 2 - 3 } & Bahan bakar baru & Bahan bakar bekas \\
\hline U235 & 0.629382 & 0.045867 \\
\hline U236 & 0.000000 & 0.084080 \\
\hline U238 & 15.232070 & 14.544671 \\
\hline Np237 & 0.000000 & 0.015104 \\
\hline Pu238 & 0.000000 & 0.007709 \\
\hline Pu239 & 0.000000 & 0.080392 \\
\hline Pu240 & 0.000000 & 0.044665 \\
\hline Pu241 & 0.000000 & 0.028125 \\
\hline Pu242 & 0.000000 & 0.018796 \\
\hline Am241 & 0.000000 & 0.000978 \\
\hline Am242m & 0.000000 & 0.000023 \\
\hline Am243 & 0.000000 & 0.006202 \\
\hline Cm242 & 0.000000 & 0.000483 \\
\hline Cm244 & 0.000000 & 0.003328 \\
\hline Total HM & 15.861452 & 14.880422 \\
\hline Total FP & & 0.981029 \\
\hline Grand Total & 15.861452 & 15.861452 \\
\hline
\end{tabular}


Tabel 2. Kandungan nuklida-nuklida dalam bahan bakar sistem PWR UOX dan MOX

\begin{tabular}{|l|l|l|l|l|l|c|}
\hline \multirow{3}{*}{ Isotop } & \multicolumn{5}{|c|}{ Kandungan(ton) } \\
\cline { 2 - 7 } & \multicolumn{2}{|c|}{ Bahan Bakar Baru } & \multicolumn{2}{c|}{ Bahan Bakar Bekas } & \multicolumn{2}{c|}{ Bahan Bakar Diproses Ulang } \\
\cline { 2 - 7 } & $\mathrm{U}$ & $\mathrm{U}-\mathrm{Pu}$ & $\mathrm{U}$ & $\mathrm{U}-\mathrm{Pu}$ & $\mathrm{U}$ & U-Pu \\
\hline U235 & 0.597913 & 0.00027 & 0.029195 & 0.000254 & 0.014383 & 0.000000 \\
\hline U236 & 0.000000 & 0.000000 & 0.053517 & 0.000004 & 0.026366 & 0.000000 \\
\hline U238 & 14.470466 & 0.089918 & 9.257683 & 0.089727 & 4.559754 & 0.000000 \\
\hline Np237 & 0.000000 & 0.000000 & 0.009614 & 0.000001 & 0.004745 & 0.000000 \\
\hline Pu238 & 0.000000 & 0.009594 & 0.004907 & 0.009506 & 0.002467 & 0.000000 \\
\hline Pu239 & 0.000000 & 0.422468 & 0.051170 & 0.361456 & 0.025200 & 0.000000 \\
\hline Pu240 & 0.000000 & 0.152034 & 0.028429 & 0.159057 & 0.014174 & 0.000000 \\
\hline Pu241 & 0.000000 & 0.082237 & 0.017902 & 0.069537 & 0.006931 & 0.000000 \\
\hline Pu242 & 0.000000 & 0.036550 & 0.011964 & 0.037366 & 0.005892 & 0.000000 \\
\hline Am241 & 0.000000 & 0.000000 & 0.000622 & 0.014769 & 0.002182 & 0.000000 \\
\hline Am242m & 0.000000 & 0.000000 & 0.000015 & 0.000104 & 0.000007 & 0.000000 \\
\hline Am243 & 0.000000 & 0.000000 & 0.003947 & 0.001959 & 0.001943 & 0.000000 \\
\hline Cm242 & 0.000000 & 0.000000 & 0.000308 & 0.000192 & 0.000000 & 0.000000 \\
\hline Cm244 & 0.000000 & 0.000000 & 0.002118 & 0.000084 & 0.000861 & 0.000000 \\
\hline Total HM & 15.068379 & 0.793073 & 9.471389 & 0.744016 & 4.664908 & 0.000000 \\
\hline Total FP & - & - & 0.624425 & 0.049057 & 0.307657 & 0.000000 \\
\hline Grand & 15.068379 & 0.793073 & 10.095814 & 0.793073 & 4.972565 & 0.000000 \\
\hline Total & & & & & & \\
\hline
\end{tabular}

Selanjutnya pada Tabel 3 diperbandingkan hasil-hasil untuk unsur-unsur aktinida minor dan metal berat dari kedua jenis PLTN tersebut.

Tabel 3. Jumlah timbunan aktinida minor (MA) dan metal berat (HM) setiap tahun yang terkandung dalam bahan bakar bekas dari PLTN $1000 \mathrm{MWe}$, dalam satuan $\mathrm{kg}$

\begin{tabular}{|c|c|c|c|c|c|c|c|c|}
\hline $\begin{array}{c}\text { Jenis Reaktor/ } \\
\text { BU }\end{array}$ & Np-237 & Am-241 & Am-242 & Am-243 & Cm-242 & Cm-244 & $\begin{array}{c}\text { Jumlah } \\
\text { MA }\end{array}$ & $\begin{array}{c}\text { Jumlah } \\
\text { HM }\end{array}$ \\
\hline $\begin{array}{l}\text { PWR-UOX/ } \\
60 \text { MWd/kg } \\
\text { PWR-MOXI } \\
60 \mathrm{MWd/kg}\end{array}$ & 5,104 & 0,098 & 0,002 & 0,620 & 0,048 & 0,333 & 6,205 & 14.880 \\
\hline
\end{tabular}

Dari data-data tersebut menunjukkan bahwa operasi PLTN jenis PWR-UOX dan sistem PWR UOX dan MOX berdaya 1000 MWe akan menghasilkan kandungan MA dalam setahun masing-masing sebesar 16,205 kg dan 43,471 kg. Dengan demikian pengoperasian PWR-MOX memang akan membuat efisien penggunaan bahan bakar tetapi di lain hal akan menghasilkan limbah MA yang jauh lebih banyak. Kandungan unsur Am-241 pada PWR-MOX jumlahnya berlipatganda dibanding pada PWR-UOX. Hal ini terjadi karena pembentukan dalam bahan bakar baru PWR-MOX terdapat kira-kira 5\% kandungan Pu-239 (lihat Tabel 2) yang merupakan nuklida asal terbentuknya Am-241. Jadi dalam pembentukan Am-241 dalam PWR-MOX berasal dari dua nuklida asal yaitu U-238 dan Pu-239, sedangkan dalam PWR-UOX pembentukannya hanya dari nuklida asal U-238.

\section{Transmutasi Unsur MA dengan Accelerator Driven System (ADS)}

Salah satu cara untuk meminimalkan keradioaktifan tersebut adalah dengan cara transmutasi, di mana limbah radioaktif yang terdiri atas nuklida-nuklida umur panjang ditransmutasi menjadi nuklida lebih stabil. Proses transmutasi dilakukan dengan mengiradiasinya pada medan neutron cepat dengan fluks yang sangat tinggi 
pada suatu reaktor nuklir. Bahan bakar reaktor ini harus bebas uranium untuk mencegah timbulnya kembali nuklida-nuklida umur panjang. Dengan ketiadaan U-235 memperkecil ßeff dan ketiadaan U-238 memperkecil efek Dopler, yang mana kedua parameter fisika reaktor tersebut berperan dalam pengendalian reaktor kritik, sehingga solusinya reaktor harus bekerja dalam mode subkritik. Reaktor subkritik yang bekerja pada fluks yang sangat tinggi memerlukan sumber neutron sangat tinggi yang dapat disediakan melalui reaksi spalasi oleh proton energi tinggi dari suatu akselerator. Sistem ini disebut sebagai Accelerator Driven System (ADS). Keistimewaan ADS dibanding transmuter jenis lainnya adalah lebih aman pengendaliannya, ploriferasi terjamin dan limbah yang dihasilkan lebih sedikit. Ciri-ciri tersebut yang mengelompokkan ADS ke dalam bagian dari sistem PLTN generasi ke IV ${ }^{(4)}$. Untuk membakar MA dapat dilakukan dengan dua cara yaitu dibakar bersama dengan unsur plutonium pada fasilitas pembakar transuranium (TRU burner), atau secara terpisah dalam fasilitas yang sepenuhnya sebagai pembakar MA (fully dedicated for MA burner).

Untuk mengetahui berapa jumlah ADS yang diperlukan, perlu diketahui kemampuan ADS dalam membakar/mentrasmutasi unsur MA dari bahan bakar bekas, dan berikut ini data-data terpublikasi dari perancang ADS.

Tabel 4. Data laju transmutasi unsur MA dalam ADS

\begin{tabular}{|c|r|c|c|}
\hline$k_{\text {eff }}$ & $\begin{array}{c}\text { Daya, } \\
\text { MWth }\end{array}$ & $\begin{array}{c}\text { Laju transmutasi } \\
\text { unsur MA, kg/th }\end{array}$ & $\begin{array}{c}\text { Laju trans. per } \\
\text { daya, kg/th.MWth }\end{array}$ \\
\hline 0,95 & 800 & 250 & 0,31 \\
099 & 400 & 138 & 0,35 \\
0,94 & 405 & 114 & 0,28 \\
0,81 & 3000 & 1100 & 0,37 \\
\hline
\end{tabular}

Perancang

Tsujimoto ${ }^{(5)}$

Rimpault ${ }^{(6)}$

Takizuka, dkk ${ }^{(5)}$

Plukiene ${ }^{(7)}$

Data tersebut menunjukkan bahwa suatu ADS di atas daya 400 MWth tidak banyak memberikan kenaikan yang berarti pada laju transmutasi. Hal ini diperkuat dengan apa yang dikemukakan oleh Rimpault yang mendapatkan data bahwa pada daya $400 \mathrm{MW}_{\text {th }}$ laju transmutasi sudah mencapai kira-kira $93 \%$ dibandingkan laju transmutasi pada $800 \mathrm{MW}_{\text {th }}{ }^{(8)}$.

Data-data pada Tabel 3 sudah tentu diperoleh dari parameter-parameter sistem yang berbeda misalnya komposisi bahan bakar, konfigurasi teras dan fraksi bakar. Tetapi secara kasar dapat diambil suatu rata-rata nilai laju transmutasi per daya adalah $0,30 \mathrm{~kg} /$ th.MWth. Jika diambil suatu ADS berdaya $400 \mathrm{MW}_{\text {th }}$, fasilitas ini akan mampu mengolah kira-kira $120 \mathrm{~kg}$ per tahun. Bila skema daur proses aktinida minor yang diambil maka berdasar data pada Tabel 3, satu ADS akan mampu melayani 7 PLTN PWR-UOX, dan jika sistem daur penggunaan plutonium kembali sebagai bahan bakar MOX yang digunakan maka dalam 3 PLTN harus disediakan satu ADS. Jadi jumlah ADS yang diperlukan tergantung pada kebijakan sistem daur yang akan diambil.

\section{KESIMPULAN}

Operasi suatu PLTN standart saat ini yang menggunakan bahan bakar UOX menghasilkan unsur-unsur aktinida minor (MA) sejumlah 16,205 $\mathrm{kg}$ per tahun, dan sebanyak $43,471 \mathrm{~kg}$ per tahun dihasilkan pada sistem PLTN yang mendaur ulang plutonium sebagai bahan bakar MOX. Inventaris MA sebanyak ini akan layak diperhatikan kaitannya dengan isu lingkungan untuk masa depan. Solusi yang dapat diusulkan adalah dengan memasukkan fasilitas ADS ke dalam sistem PLTN untuk mentransmutasi aktinida minor. Hasil-hasil perhitungan menunjukkan bahwa satu ADS $400 \mathrm{MW}_{\text {th }}$ diperlukan untuk melayani operasi 12 buah PLTN PWR bila hanya limbah MA yang dijadikan obyek perhatian. Bila dalam sistem yang mendaur ulang plutonium sebagai bahan bakar MOX, maka tiga buah ADS diperlukan dalam sistem tersebut. Suatu fasilitas ADS yang diintegrasikan dalam sistem PWR UOX dan MOX akan menjadi suatu opsi pengembangan energi nuklir di masa depan yang bercorak pada lebih ramah lingkungan dan efisiensi penggunaan bahan bakar. 


\section{DAFTAR PUSTAKA}

1. www-nfcis.iaea.org: Integrated Nuclear Fuel Cycle Information System

2. W. GODOWSKY, Partition and Transmutation as a Waste Management Option, Materials of Workshop on Technology and Applications of ADS, ICTP-Italy, 17-28 October 2005, p55

3. W. GODOWSKY, Partition and Transmutation as a Waste Management Option, Materials of Workshop on Technology and Applications of ADS, ICTP-Italy, 17-28 October 2005, p88

4. S. SOENTONO, "Opsi Nuklir dan Keselamatan PLTN", Prosiding Seminar Nasional ke-9 Teknologi dan keselamatan PLTN, P2SRM-BATAN, Jakarta 20 Agustus 2003, p16

5. T. MUKAIYAMA, "Safeguards Aspects of High_Power Proton Accelerator-Driven Systems", Proceedings of 3rd Workshop on Science and Modern Technology for Safeguards, International House of Japan, Tokyo, Japan, 13-16 November, 2000, p135

6. G. RIMPAULT, Objectives of an ADS core dedicated to transmutation, Topical Day: November 23rd 2004, SCK-CEN Mol, Belgium, p17

7. R. PLUKIENE, Evolution of Transuranium Isotopic Composition in Power Reactors and Innovative Nuclear Systems for Transmutation, The Summary of the doctoral thesis - Physical Sciences - Physics (2P), Vytautas Magnus University, Lithuania, 2003, p10

8. G. RIMPAULT, Objectives of an ADS core dedicated to transmutation, Topical Day: November 23rd 2004, SCK-CEN Mol, Belgium, p16 